\title{
Immediate induction of labor in premature rupture of membranes at term (PROMT)-vaginal Misoprostol tablet versus PGE2 gel: a randomized comparative study
}

\author{
Snehamay Chaudhuri ${ }^{1 *}$, Sankar Nath Mitra ${ }^{1}$, Pradip Kumar Banerjee ${ }^{2}$, \\ Pranab Kumar Biswas ${ }^{3}$, Sudipta Bhattacharrya ${ }^{4}$
}

\begin{abstract}
${ }^{1}$ Department of Obstetrics and Gynecology, Midnapore Medical College, Medinipur, West Bengal, India ${ }^{2}$ Department of Obstetrics and Gynecology, NRS Medical College, Kolkata, West Bengal, India ${ }^{3}$ Department of Obstetrics and Gynecology, National Medical College, Kolkata, West Bengal, India ${ }^{4}$ Department of Pathology, NRS Medical College, Kolkata, West Bengal, India
\end{abstract}

Received: 20 July 2018

Accepted: 28 August 2018

\section{*Correspondence:}

Dr. Snehamay Chaudhuri,

E-mail: snehamay_chaudhuri_dr@yahoo.com

Copyright: ( ) the author(s), publisher and licensee Medip Academy. This is an open-access article distributed under the terms of the Creative Commons Attribution Non-Commercial License, which permits unrestricted non-commercial use, distribution, and reproduction in any medium, provided the original work is properly cited.

\section{ABSTRACT}

Background: The aim of the study is to compare immediate induction with vaginal misoprostol tablet and immediate induction with vaginal PGE2 gel in women with premature rupture of membranes at term (PROMT).

Methods: Nine hundred thirty-two women with PROM at term were assigned randomly to receive intravaginal $25 \mu \mathrm{g}$ misoprostol tablet, 4 hourly with a maximum of 5 doses or $0.5 \mathrm{mg}$ vaginal PGE2 gel 6 hourly with a maximum of 2 doses. The primary outcome measures were cesarean section rate, admission to delivery interval and induction to delivery interval. Secondary outcomes included, mode of delivery, and maternal and neonatal safety outcome. Results were calculated applying Fisher Exact Test, Chi square test, $t$ test and calculating the P-value using an alpha level of 0.05 for Type I error.

Results: The mean time from admission to delivery was 13.16 hours in the misoprostol group and 13.56 hours in the PGE2 group $(\mathrm{P}=0.3014)$. Induction to delivery interval was also comparable between the groups $(10.23 \mathrm{~h}$ versus 10.18 h).Caesarean section rate did not differ significantly between groups $(12.13 \%$ versus $15.74 \%, \mathrm{P}=0.135 \mathrm{RR}$ 0.783 95\% CI 0.568-1.079).More women in misoprostol group had instrumental delivery (7.57\% versus $4.25 \%$, $\mathrm{P}=0.031$, RR 1.089 95\% CI 1.04-3.03). The neonatal outcomes were comparable between the groups . Maternal outcomes were not significantly different except incidence of analgesic use ( $\mathrm{P}=0.009 \mathrm{RR} 1.62$ 95\% CI 1.03-1.30), meconium stained liquor $(\mathrm{P}=.0096 \mathrm{RR} 2.03 \mathrm{CI} 1.17-3.53)$ and number of digital vaginal examinations $(\mathrm{P}<.0001)$ in misoprostol group.

Conclusions: Vaginal misoprostol is equally efficacious in labor induction and demonstrates a similar fetal and maternal safety profile to PGE2 gel.

Keywords: Dinoprostone, Induction of labor, Misoprostol, PGE2 gel, Premature rupture of membranes at term, PROM

\section{INTRODUCTION}

Premature rupture of membranes (PROM), is defined as rupture of membranes before onset of labor, complicates
$5-10 \%$ of pregnancies. At least $60 \%$ of cases of PROM occur at term. ${ }^{1}$ The concern with conservative management is the risk of infection to the mother and the 
fetus whereas immediate induction can increase cesarean rate. $^{2}$

A recent systematic review and meta-analysis of randomized control trials has showed that the risk of cesarean delivery following labour induction was significantly lower than the risk associated with expectant management. ${ }^{3}$ Results of the International Term PROM Trial suggest that immediate induction results in greater maternal satisfaction and lower risk of maternal infection than expectant treatment. ${ }^{4}$

For induction of labour many methods have been tested, but prostaglandins remain a preferred method for cervical ripening and labor induction..$^{5}$ Our previous study has compared expectant management and immediate induction with PGE2 gel in women with PROM at term and has showed immediate induction with PGE2 gel results in lower caesarean section rate without any increase in maternal and neonatal infectious morbidity. ${ }^{6}$ Several other studies have shown favorable results for induction of labor with PGE2 in women with PROM at term. $^{7-9}$

Misoprostol, a prostaglandin E1 analogue, has been shown to be an effective labor induction agent. A recent meta-analysis quantified the effects and safety of different prostaglandins used for labor induction and has shown titrated low dose oral solution is the safest in terms of risk of caesarean section, while vaginal misoprostol tablets $(\geq 50 \mu \mathrm{g})$ are the most effective in achieving vaginal delivery within 24 hours of induction. ${ }^{5}$

However, misoprostol has not been compared extensively with PGE2 in studies designed exclusively for women with PROM at term. Authors compared vaginal application of PGE2 gel with intravaginal misoprostol in women with PROM at or after 37 weeks of gestation who were undergoing intentional immediate labor induction. Present study hypotheses were that immediate induction with vaginal misoprostol will result in fewer caesarean section and significant shortening of induction to delivery time in comparison to immediate induction with vaginal PGE2 gel.

\section{METHODS}

This trial was conducted from August 2006 to May 2013 at the Department of Gynecology and Obstetrics of a tertiary care hospital. All participants provided written informed consent before enrolment. Institutional Ethics Committee approved the protocol (no NMC/ Ethi/ Gen$25 / 3926$ dated 27/07/2006) and this trial was registered as a Clinical Trial, numbered-NCT00355303 (www clinicaltrials.gov).

\section{Inclusion criteria}

Women were eligible for entry into the trial if they had ruptured membranes at $\geq 37$ weeks of gestation, had a single fetus in cephalic presentation and were not in labor. The time of spontaneous rupture of membranes was noted.

Diagnosis was based on (i) clinical history of passage of liquor (ii) pooling of fluid in posterior fornix as seen by speculum examination (iii) palpation through cervical canal for absence of membranes and (iv) reduced liquor volume on sonography (AFI <5) in selected women where clinical findings were inconclusive. No other tests of spontaneous rupture of membranes, such as $\mathrm{pH}$ of the vagina or the presence of ferns on microscopy were made.

\section{Exclusion criteria}

Women were excluded from the study if they were in labor (onset of labor was defined as regular contractions occurring twice in 10 minutes by abdominal palpation) or if there was a contraindication to induction of labor (such as placenta previa, meconium staining of amniotic fluid). Women with history of previous caesarean delivery were also excluded.

\section{Randomization schedule}

Randomization was done by simple randomization method using a table of random numbers (Fisher RA and Yates F). The schedule was constructed so that the number in each group would be balanced for every 20 women recruited. The group assignments were put into sealed envelopes. The envelopes were opened when the women were recruited by attending physician, which was the point of randomization. The routes of administration, drug dosage were not blinded.

\section{Treatment schedule}

On admission to the delivery room complex, the time of spontaneous rupture of membranes was noted. If the inclusion criteria were met, informed consent for inclusion in the study was requested by the medical staff and no woman refused it. At the time of diagnosis of rupture of membranes, Bishop's scoring was also done, following which uterine contractions and fetal heart rate was monitored using electronic fetal monitoring for one hour. If the fetal heart rate was normal and if contractions were not present, women were randomly allotted to either immediate induction with misoprostol or immediate induction with PGE2 gel group. Prophylactic antibiotic either of a penicillin group or a cephalosporin group, depending on the availability of the antibiotic in the hospital was given.

Women assigned to group 1 were given misoprostol $25 \mu \mathrm{g}$ tablet in the posterior vaginal fornix every $4 \mathrm{~h}$, up to a maximum of five doses. Women in group 2 were given $0.5 \mathrm{mg}$ PGE2 gel instilled in the posterior vaginal fornix every $6 \mathrm{~h}$ up to a maximum of two doses. Drugs were administered by Trainee Residents and application of 
inducing agents were stopped if the woman was in active phase of labor (Cervical dilatation $\geq 3 \mathrm{~cm}$ and uterine contractions $3 / 10 \mathrm{~min}$ ). If the contractions subsequently became inadequate, oxytocin infusion was used to augment labor so that three contractions were obtained in 10 minutes or a maximum dose of oxytocin $(32 \mathrm{miu} / \mathrm{min})$ was achieved. The women were carefully monitored every half hour for side effects and onset and progress of labor. Vaginal examination was performed every 4 hours to assess the progress of labor. Abnormal labor was defined very specifically. Failure to progress in the latent phase was defined as a period of 24 hours in primigravidas and 14 hours in multigravidas without progress. Failure to progress in active phase of labor was defined as failure of further cervical dilatation after $3 \mathrm{~cm}$ dilatation or of descent of the presenting part after 2 hours of adequate uterine contractions. Failure to progress in the second stage of labor was defined as the absence of further descent of presenting part over a period of 2 hours in primigravida and 1 hour in multigravida in spite of adequate uterine activity. At delivery Apgar scores were determined. Babies in both the groups had a blood sample taken for white cell counts and culture within 24 hours of birth and before treatment with antibiotics. Other tests and treatment given to the babies were determined by attending pediatricians.

\section{Outcome measures}

Present primary outcome measures were caesarean section rate, induction to delivery interval and admission to delivery interval. Secondary outcome measures were maternal morbidity, neonatal morbidity and mortality.

The fetal heart rate was monitored by using electronic fetal monitoring during one hour of observation and first two hours of administration of inducing agents. Intermittent auscultation was performed every hour before onset of labor and every half hour during labor. If fetal heart rate was abnormal in intermittent auscultation continuous electronic fetal monitoring was performed throughout labor. The changes in fetal heart rate that were considered abnormal included persistent decelerations (early, late, or variable decelerations), fetal tachycardia (fetal heart rate $>160$ beats per minute), fetal bradycardia (fetal heart rate $<100$ beats per minute) or reduced short term variability $(<5$ beats per minute). Failure of induction was defined as no onset of labor after 24 hours following initiation of induction of labor. Tachysystole was defined as at least six contractions in 10 minutes. Hyperstimulation was defined as the presence of tachysystole associated with fetal tachycardia, late decelerations, or loss of beat-to-beat variability. Recognized episodes of hyperstimulation were managed with change in maternal position, oxygen administration, and $250 \mu \mathrm{g}$ of terbutaline given subcutaneously.

Hypertonus was defined as uterine contraction lasting at least for two minutes. The occurrence of chorioamnionitis (maternal fever usually associated with maternal and fetal tachycardia, uterine tenderness, and peripheral leukocytosis) and postpartum endometritis (presence of maternal fever and uterine tenderness, leukocytosis, and foul-smelling lochia) was evaluated in all patients. Sepsis in the neonate was defined as at least one positive blood culture believed not to be a contaminant. The physicians who managed labor were not blinded to study group allocation.

\section{Sample size}

Using the results of present earlier studies authors calculated that a sample size of 914 women would give $80 \%$ power to detect a $40 \%$ difference in caesarean section from $15 \%$ in the vaginal PGE 2 gel group to $9 \%$ in the misoprostol group $(\mathrm{P}<0.05)$, a 4 hours detectable shortening of time interval in regard to induction to delivery interval and admission to delivery interval in misoprostol group than PGE2 gel group (power 90\%, $\mathrm{P}<0.05) ., 10$

\section{Statistical analysis}

All data were collected in a proforma prepared for the study. The data were analyzed with Epi info software and Microsoft excels software. Analyses were done with intention to treat principle. All the women who underwent randomization and for whom outcome data were available were included in the analysis. Authors did not have prespecified stopping rule based on superiority of regimen before the trial ended. Results were calculated applying Fisher Exact Test, Chi square test, T test and calculating the P-value using an alpha level of 0.05 for Type I error.

\section{RESULTS}

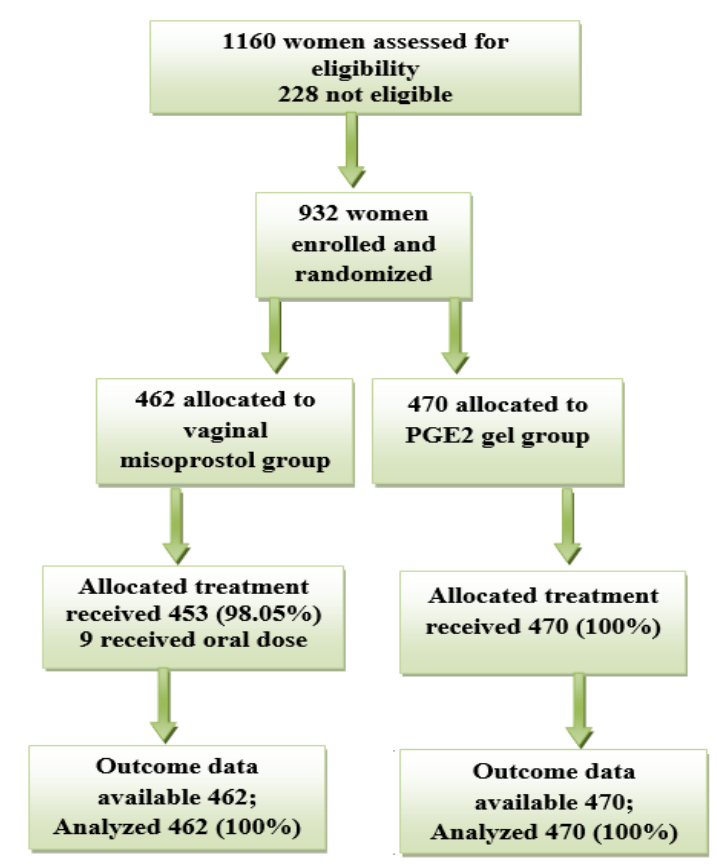

Figure 1: Trial profile. 
Of the 1160 women eligible for admission into the study, 228 women were not included because of various reasons (Gestational age <37 weeks, fetal distress, meconium stained amniotic fluid, breech and compound presentation, contractions started during observation, intact membranes, women not willing to participate).

Following randomization of 932 women, 462 women were included in misoprostol group and 470 women in PGE2 gel group. Of the 462 women in misoprostol group, 8 women had improper administration of misoprostol (oral) and one woman refused the treatment with misoprostol after first dose (Figure 1).

The two groups of women were similar with regard to control variables (Table 1) and there were no statistically significant differences between the groups with respect to time between PROM and admission to hospital or the principal methods used to confirm the occurrence of PROM.

Table 1: Baseline characteristics at the entry into the trial.

\begin{tabular}{|c|c|c|c|}
\hline Characteristics & $\begin{array}{l}\text { Immediate induction } \\
\text { with misoprostol } \\
\text { (Group I } n=462 \text { ) }\end{array}$ & $\begin{array}{l}\text { Immediate induction } \\
\text { with PGE2 gel } \\
\text { (Group II } n=470 \text { ) }\end{array}$ & P value \\
\hline Maternal age (years) $\dagger$ & $22.8 \pm 3.58$ & $22.4 \pm 3.62$ & $0.9549^{*}$ \\
\hline Gestational age (weeks) $\dagger$ & $38.36 \pm 1$ & $38.46 \pm 1.5$ & $1.0^{*}$ \\
\hline \multicolumn{4}{|l|}{ Parity } \\
\hline 0 & $392(84.84 \%)$ & $392(83.5 \%)$ & \multirow{2}{*}{$0.5464 * *$} \\
\hline$>1$ & $70(15.15 \%)$ & $78(16.5 \%)$ & \\
\hline Ultrasound needed to confirm gestational age & $387(83.7 \%)$ & $421(89.5 \%)$ & $0.009^{* *}$ \\
\hline Interval from rupture of membranes to admission (hours) $\dagger$ & $4.94 \pm 4.53$ & $5.0 \pm 5.13$ & $0.4249^{* *}$ \\
\hline \multicolumn{3}{|l|}{ Methods of confirming rupture of membranes } & \multirow{4}{*}{$0.349^{* *}$} \\
\hline Pooling of amniotic fluid on speculum examination & $440(95.2 \%)$ & $446(94.8 \%)$ & \\
\hline Absence of membranes on digital examination & $387(83.7 \%)$ & $431(91.7 \%)$ & \\
\hline Reduced liquor volume $(\mathrm{AFI}<5)$ on USG & $97(20.9 \%)$ & $87(18.51 .2 \%)$ & \\
\hline \multicolumn{4}{|l|}{ Bishop's score } \\
\hline$>6$ & $229(49.56 \%)$ & $240(51.0 \%)$ & \multirow{2}{*}{$0.6477^{* *}$} \\
\hline$<6$ & $233(50.43 \%)$ & $230(49 \%)$ & \\
\hline
\end{tabular}

Table 2: Methods of inducing labour and use of oxytocin during labour.

\begin{tabular}{|lll|}
\hline Method & $\begin{array}{l}\text { Immediate } \\
\text { induction with } \\
\text { misoprostol } \\
\text { (Group I n=462) }\end{array}$ & $\begin{array}{l}\text { Immediate } \\
\text { induction with } \\
\text { PGE2 gel } \\
\text { (Group II n=470) }\end{array}$ \\
\hline $\begin{array}{l}\text { PGE2 single } \\
\text { application }\end{array}$ & - & $396(84.25 \%)$ \\
\hline $\begin{array}{l}\text { Repeat PGE2 } \\
\text { application }\end{array}$ & - & $74(15.74 \%)$ \\
$\begin{array}{l}\text { Oxytocin } \\
\text { during labor }\end{array}$ & - & $53(11.27 \%)$ \\
\hline $\begin{array}{l}\text { Misoprostol } \\
\text { One dose }\end{array}$ & $145(31.38 \%)$ & - \\
\hline $\begin{array}{l}\text { Two doses } \\
\text { Three doses }\end{array}$ & $75(172(37.22 \%)$ & - \\
\hline $\begin{array}{l}\text { Four doses } \\
\text { Four doses }\end{array}$ & $11(2.37(12.33 \%)$ & - \\
\hline $\begin{array}{l}\text { Oxytocin } \\
\text { during labor }\end{array}$ & $26(5.62 \%)$ & - \\
\hline
\end{tabular}

Methods of inducing labor are shown in Table 2. Sixty nine percent women had onset of labor after 2 doses of misoprostol in Group I and $84 \%$ women had onset of labor after single application of PGE2 gel, in group II.

\section{Primary outcome}

Results for the primary outcome variable, are presented in Table 3, Table 4 and Table 5. The rate of cesarean section did not differ significantly between groups (Table 3 ) but operative vaginal delivery rate was significantly higher in group I women (35\%vs $20 \% ; \mathrm{P}=0.031$ Relative Risk (RR) $1.08995 \%$ Confidence Interval (CI) 1.043.03).

Induction failure as a cause of caesarean section was more common in group II than group I $(\mathrm{P}=.0294$ RR.5368 95\% CI.3087-9398). Cesarean section rate was not different in respect to abnormal fetal heart rate, parity or Bishop's score (Table 4). 
As can be seen in Table 5, there were no significant differences between the two treatment groups for time interval from induction to onset of labor, duration of active labor, induction to delivery interval, time in hospital before delivery and interval from membranes rupture to delivery.

Table 3: Mode of delivery.

\begin{tabular}{|c|c|c|c|c|}
\hline Mode of delivery & $\begin{array}{l}\text { Immediate induction } \\
\text { with misoprostol }(n=462)\end{array}$ & $\begin{array}{l}\text { Immediate induction } \\
\text { with PGE2 gel }(n=470)\end{array}$ & P value* & $\begin{array}{l}\text { Relative risk } \\
(95 \% \mathrm{CI})^{* *}\end{array}$ \\
\hline Caesaraen section & $57(12.33 \%, 57 / 462)$ & $74(15.74 \%, 57 / 470)$ & 0.135 & R $0.783(0.568-1.079)$ \\
\hline & & & & R 1.089 (1.04-3.03) \\
\hline Spontaneous vaginal delivery & $370(80.08 \%, 370 / 462)$ & $376(80.0 \%, 376 / 470)$ & 0.975 & R $1.00(0.93-1.00)$ \\
\hline
\end{tabular}

${ }^{*} \chi{ }^{2}$ Test $* * \mathrm{CI}-$ confidence interval

Table 4: Characteristics of caesarean delivery.

\begin{tabular}{|c|c|c|c|c|}
\hline Variables & $\begin{array}{l}\text { Immediate induction } \\
\text { with misoprostol }(n=462)\end{array}$ & $\begin{array}{l}\text { Immediate induction } \\
\text { with PGE2 gel }(n=470)\end{array}$ & $\begin{array}{l}\text { P } \\
\text { value }^{*}\end{array}$ & Relative risk (CI**) \\
\hline \multicolumn{5}{|l|}{ Indication of LSCS } \\
\hline Induction failure & $18(3.89 \% ; 18 / 462)$ & $34(7.23 \% .34 / 470)$ & 0.0294 & R 0.5368 (0.3087-9398) \\
\hline Abnormal fetal heart & $22(4.76 \% ; 22 / 462)$ & $15(3.19 \% ; 15 / 470)$ & 0.219 & R 1.4921 (0.7839-2.8399) \\
\hline Others & $17(3.67 \% 17 / 462)$ & $25(5.31 \% ; 25 / 470)$ & 0.226 & R $0.6918(0.3787-1.2638)$ \\
\hline \multicolumn{5}{|l|}{ Parity } \\
\hline Nulliparous & $53(13.52 \% ; 53 / 392)$ & $74(18.87 \% ; 74 / 392)$ & 0.162 & R 0.7974 (0.5797-1.0968) \\
\hline Multipara & $04(5.71 \% ; 4 / 70)$ & $0(0 / 78)$ & & \\
\hline \multicolumn{5}{|l|}{ Bishop's score } \\
\hline$\geq 6$ & $26(11.40 \% 26 / 228)$ & $30(12.5 \% ; 30 / 240)$ & 0.624 & R 0.8817 (0.5298-1.4671) \\
\hline$\overline{<} 6$ & $31(13.30 \% ; 31 / 233)$ & $44(19.13 \% ; 44 / 230)$ & 0.137 & R .7167 (.461-1.1143) \\
\hline
\end{tabular}

${ }^{*} \chi^{2}$ Test **CI-95\% Confidence interval

Table 5: Timing of events after induction.

\begin{tabular}{|c|c|c|c|}
\hline Time (hours) § & $\begin{array}{l}\text { Immediate induction with } \\
\text { misoprostol }(\mathrm{n}=\mathbf{4 6 2})\end{array}$ & $\begin{array}{l}\text { Immediate induction } \\
\text { with PGE2 gel }(n=470)\end{array}$ & P value* \\
\hline Time to active labor $\dagger$ & $5.02 \pm 3.49$ & $5.34 \pm 4.81$ & 0.1224 \\
\hline Duration of active labor $\uparrow, \ddagger$ & $4.32 \pm 2.61$ & $3.18 \pm 1.74$ & 1.0 \\
\hline Induction to delivery interval & $10.23 \pm 6.07$ & $10.18+7.09$ & 0.5255 \\
\hline Time in hospital before delivery & $13.16 \pm 6.50$ & $13.56 \pm 6.47$ & 0.3014 \\
\hline Interval from membranes rupture to delivery & $16.80 \pm 7.33$ & $17.53 \pm 7.93$ & 0.4088 \\
\hline
\end{tabular}

$\dagger 18$ women in misoprostol group had induction failure and did not went in labor, excluded from analysis, $\$ 34$ women in PGE2 group had induction failure and 15 women had fetal distress before onset of active labor, excluded from analysis, § values are mean \pm standard deviation, *T test

\section{Secondary outcome}

Secondary outcome measures are shown in Table 6 and 7. Maternal outcome in regard to clinical chorioamnionitis, abnormal fetal heart rate, vomiting, hypertonus, tachysystole, hyperstimulation, postpartum fever and post-partum hemorrhage were similar in both the groups (Table 5). But the incidence of analgesic use $(\mathrm{P}=0.009$ RR 1.62 95\% CI 1.03-1.30), meconium stained liquor $(\mathrm{P}=.0096 \mathrm{RR} 2.03 \mathrm{CI} 1.17-3.53)$ and number of digital vaginal examinations $(\mathrm{P}<.0001)$ was significantly higher in group I than Group II.
Blood samples were taken for white cell count and culture in more than $75 \%$ of babies in the two groups. The rate of neonatal infection and stay in neonatal intensive care unit did not differ between groups (Table 7). Other parameters were comparable between the groups. Eight babies, 4 in each group died. In group I, all four babies were born with low Apgar score and causes of death were asphyxia. In group II, two babies were delivered asphyxiated with low Apgar score and died. Another two babies although born with normal Apgar score, were low birth weight $(2.1 \mathrm{~kg}$ and $2.2 \mathrm{~kg})$ and died of infection after 3 days of birth. 
Table 6: Maternal outcome.

\begin{tabular}{|c|c|c|c|c|}
\hline Outcome measures & $\begin{array}{l}\text { Immediate induction } \\
\text { with misoprostol }(n=462)\end{array}$ & $\begin{array}{l}\text { Immediate induction } \\
\text { with PGE2 gel }(n=470)\end{array}$ & $\mathbf{P *}$ value & $\begin{array}{l}\text { Relative risk } \\
(95 \% \mathrm{CI})\end{array}$ \\
\hline Clinical chorioamnionitis & 0 & 0 & & \\
\hline Analgesic use & $279(60.38 \%)$ & $244(51.91 \%)$ & 0.009 & R $1.62(1.03-1.30)$ \\
\hline Abnormal fetal heart rate & $31(6.70 \%)$ & $30(06.38 \%)$ & 0.840 & R1.05 (0.64-0.70) \\
\hline Meconium stained liquor & $36(7.79 \%)$ & $18(3.82 \%)$ & 0.0096 & R 2.03(1.17-3.53) \\
\hline Tachysystole & $18(3.67 \%)$ & $7(1.48 \% \%)$ & $0.018 * *$ & R $2.616(1.013-6.204)$ \\
\hline Hypertonus & $8(1.94 \%)$ & $10(2.12 \%)$ & $0.812 * *$ & R $0.81(0.32-2.04)$ \\
\hline Hyperstimulation & $20(4.32 \%)$ & $12(2.55 \%)$ & $0.095 * *$ & R 1.69 (0.83-3.42) \\
\hline Vomiting & $5(1.08 \%)$ & $5(1.02 \%)$ & $1.00 * *$ & R 1.01(0.29-3.49) \\
\hline \multicolumn{5}{|l|}{ Antibiotic used } \\
\hline Penicillin & $106(22.94 \%)$ & $88(18.72 \%)$ & 0.112 & R $1.22(0.95-1.57)$ \\
\hline Cephalosporin & $356(77.05 \%)$ & $382(81.27 \%)$ & 0.112 & R $0.94(0.88-1.01)$ \\
\hline \multicolumn{5}{|c|}{ Number of vaginal digital examination } \\
\hline$<4$ & $149(32,25 \%)$ & $294(62.55 \%)$ & $<.0001$ & R $0.51(0.44-0.59)$ \\
\hline $4-8$ & $300(64.93 \%)$ & $167(35.53 \%)$ & $<0.0001$ & R $1.82(1.59-2.1)$ \\
\hline$>8$ & $13(2.81 \%)$ & $9(1.91 \%)$ & $0.395 * *$ & R $1.46(0.53-3.40)$ \\
\hline Post-partum haemorrhage & $5(1.08 \%)$ & $8(1.70 \%)$ & $0.578 * *$ & R $0.63(0.20-1.92)$ \\
\hline Post-partum fever & $14(3.03 \%)$ & $9(1.91 \%)$ & $0.297 * *$ & R $1.58(0.69-3.62)$ \\
\hline
\end{tabular}

${ }^{*} \chi^{2}$ test, ${ }^{* *}$ Fisher exact test one tailed value

Table 7: Neonatal outcome.

\begin{tabular}{|c|c|c|c|c|}
\hline Outcome measures & $\begin{array}{l}\text { Immediate induction } \\
\text { with misoprostol } \\
(\mathrm{n}=462)\end{array}$ & $\begin{array}{l}\text { Immediate induction } \\
\text { with PGE2 gel } \\
(\mathrm{n}=470)\end{array}$ & P value* & $\begin{array}{l}\text { Relative risk } \\
(95 \% \mathrm{CI})\end{array}$ \\
\hline \multicolumn{5}{|l|}{ Apgar score } \\
\hline$<7$ at $1 \mathrm{~min}$ & $110(23.80 \%)$ & $93(19.78 \%)$ & 0.137 & R $1.20(0.94-1.53)$ \\
\hline$<7$ at $5 \mathrm{~min}$ & $18(3.89 \%)$ & $25(5.31 \%)$ & 0.300 & R $0.73(0.40-1.32)$ \\
\hline Ventilation after initial resuscitation & $27(5.84 \%)$ & $29(6.17 \%)$ & 0.832 & R $0.94(0.56-1.57)$ \\
\hline Stay in intensive neonatal care unit & $66(14.28 \%)$ & $49(10.42 \%)$ & 0.073 & R 1.37 (0.96-1.93) \\
\hline Neonatal antibiotics & $66(14.28 \%)$ & $49(10.42 \%)$ & 0.073 & R 1.37 (0.96-1.93) \\
\hline Neonatal infection & $49(10.60 \%)$ & $34(7.23 \%)$ & 0.071 & R $1.46(0.96-2.22)$ \\
\hline Neonatal seizure & $5(1.08 \%)$ & $5(1.06 \%)$ & $1.0 * *$ & R $1.01(0.29-3.49)$ \\
\hline Neonatal death & $04(0.86 \%)$ & $04(0.85 \%)$ & $1.0 * *$ & R $1.01(0.25-4.04)$ \\
\hline
\end{tabular}

* $\chi^{2}$ test with Yates correction done whenever necessary, ** Fisher exact test one tailed value

\section{DISCUSSION}

There are many studies that have compared either intra vaginal application of misoprostol or PGE2 gel for induction of labor in patients with PROM at and near term and found to be of benefit. , $^{7,11,12}$ However,' head to head' comparison of vaginal misoprostol with PGE2 gel for immediate induction of labor in women with premature rupture of membranes at term was not available until authors initiated this trial in 2006. Authors published the initial results of this trial which tested the hypothesis that use of vaginal misoprostol results in significant shortening of induction to delivery interval when compared with PGE2 gel. ${ }^{10}$ The study was further continued as a much larger sample size was needed to demonstrate that vaginal misoprostol use will result in fewer caesarean section in comparison to PGE2 gel.
Present study shows vaginal misoprostol was not associated with significant differences in caesarean section rate, time in hospital before delivery, induction to delivery interval, or maternal and neonatal infectious morbidity when compared with vaginal PGE2 gel in women with term PROM. Vaginal misoprostol was associated with increased need of operative vaginal delivery, higher incidence of meconium stained liquor, analgesic use and more number of digital vaginal examination.

Present study suggests that vaginal misoprostol may offer similar efficacy to PGE2 gel for induction of labor after PROM at term. These findings do not support the research hypothesis that vaginal misoprostol results in reduced rate of caesarean delivery or shorter length of labor than intravaginal PGE2 gel. This negative finding 
may have resulted from relatively low dosage of misoprostol used in present study.

Several investigators have compared immediate induction with $25 \mu \mathrm{g}$ vaginal misoprostol with immediate or delayed induction with oxytocin in women with PROM at term. ${ }^{11}$ 13 These studies have shown misoprostol to have equal efficacy and similar adverse effects with immediate induction with oxytocin or more effective than expectant treatment followed by oxytocin. ${ }^{11-13}$ Mean induction to delivery time, cersarean section rate of misoprostol group in present study and other secondary outcomes like maternal and perinatal outcome are in agreement with misoprostol group of these studies.

Several studies have been conducted that have compared $25 \mu \mathrm{g}$ vaginal misoprostol with PGE2 preparations $(0.5$ $\mathrm{mg}, 2 \mathrm{mg}, 3 \mathrm{mg}$ ) for induction of labor in women without PROM and have found misoprostol was equally effective or more effective than PGE2 with similar maternal and neonatal outcome. ${ }^{14-16}$

Present findings indicate that vaginal misoprostol presents a similar safety profile to PGE2 gel, although the increased incidence of meconium stained liquor in misoprostol group is concerning.

Strength of the study: Present study is the largest to date of vaginal misoprostol and PGE2 gel for the treatment of women with term PROM and was large enough to detect clinically important differences in caesarean delivery and induction to delivery interval. Present results provide reliable evidence on the use of vaginal misoprostol for induction of labor in women with premature rupture of membranes at term and contribute to the available information about its safety.

Weakness of the study: Present study was not blinded because it was not financially or technically feasible. Neonatal caregivers were not masked to subject allocation, but bias would be unlikely to influence neonatal treatment decisions. Present primary outcomes, caesarean section rate and time interval to delivery, was unlikely to be influenced as attending physicians at birth having no vested interest in study conclusion.

\section{CONCLUSION}

In conclusion present study was unable to demonstrate any advantage for misoprostol over PGE2 gel with regard to mode of delivery and induction to delivery interval following PROM. Present findings support the relative safety of misoprostol compared to PGE2 gel.

\section{ACKNOWLEDGMENTS}

Authors are grateful to all women, the doctors, nurses, trainees and other staffs of present hospital without whose collaboration this study would not have been possible.
Funding: No funding sources

Conflict of interest: None declared

Ethical approval: The study was approved by the Institutional Ethics Committee (approval letter no. NMC/Ethi/Gen-25/3926 dated 27/07/2006)

\section{REFERENCES}

1. Duff P. Premature rupture of membranes at term. N Engl J Med. 1996;334:1053-4.

2. George SS, Gangarani VS, Shesadri L. Term PROMa 12 hour expectant management. J Obstet Gynecol India. 2003;53:230-3.

3. Mishanina E, Rogozinska E, Thatthi T, Uddin-Khan $\mathrm{R}$, Khan KS, Meads C. Use of labour induction and risk of cesarean delivery: a systematic review and metanalysis. CMAJ. 2014;186(9):665-73.

4. Hannah ME, Ohlsson A, Farine D, Hewson SA, Hodnett ED, Myhr TL, et al. Induction of labor compared with expectant management of labor for prelabor rupture of membranes at term. N Eng $\mathbf{J}$ Med. 1996;334:1005-10.

5. Alfirevic Z, Keeney E, Dowswell T, Welton NJ, Dias $\mathrm{S}$, Jones LV, et al. Labour induction with prostaglandins: systematic review and network metaanalysis. BMJ. 2015;350:h217.

6. Chaudhuri S, Mitra SN, Biswas PK, Bhattacharyya S. Premature rupture of membranes at term: immediate induction with PGE2 gel compared with delayed induction with oxytocin. J Obstet Gynecol India. 2006;56(3):224-9.

7. Carbonne B, Goffinet F, Cabrol D. Vaginal administration prostaglandin $\mathrm{E} 2$ in premature ruptured membranes at term with an unfavorable cervix. J Gynecol Obstet Biol Reprod. 1996;25(8):783-91.

8. Larranaga-Azcarate C, Campo- Molina G, PerezRidriguez AF, Ezcurdia- Gurpedui M. Dinoprostone vaginal slow-release system (Propess) compared to expectant management in the active treatment of premature rupture of the membranes at term: impact on maternal and fetal outcomes. Acta Obstet Gynecol Scand. 2008;87(2):195-200.

9. Ben-Haroush A, Yogev Y, Glickman H. Mode of delivery in pregnancies with premature rupture of membranes at or before term following induction of labor with vaginal prostaglandin E2. Am J Peinatol. 2004;21:263-8.

10. Chaudhuri S, Mitra SN, Banerjee PK, Biswas PK, Bhattacharyya S. Comparison of vaginal misoprostol tablets and prostaglandin E2 gel for the induction of labor in premature rupture of membranes at term: A randomized comparative trial. J Obstet Gynaecol Res. 2011;37(11):1564-71.

11. Wing DA, Paul RH. Induction of labor with misoprostol for premature rupture of membranes beyond thirty-six weeks' gestation. Am J Obst Gynecol. 1998;179(1):94-9.

12. Zeteroglu S, Eugin- Ustin Y, Guvercinci M, Sahin G, Kamaci M. A prospective randomized study 
comparing misoprostol and oxytocin for premature rupture of membranes at term. J Matern Fetal Neonatal Med. 2006;19(5):283-7.

13. Krupa FDG, Cecatto GJ, Surita FGC, Milanez HMBP, Parpinelli MA. Misoprostol versus expectant management in premature rupture of membranes at term. BJOG. 2005;112:1284-90.

14. Nanda S, Singhal SR, Papneja A. Induction of labour with intravaginal misoprostol and prostaglandin E2 gel: a comparative study. Trop Doct. 2007;37(1):214.

15. Prager M, Enorth-Gimfors E, Edlund M, Marions L. A randomised controlled trial of intravaginal dinoprostone, intravaginal misoprostol and transcervical balloon catheter for labor induction. BJOG. 2008;115(11):1443-50.
16. Calder AA, Loughney AD, Weir CJ, Barber JW. Induction of labor in nulliparous and multiparous women: a UK, multicentre, open-label study of intravaginal misoprostol in comparison with dinoprostone. BJOG. 2008;115(10):1279-88.

Cite this article as: Chaudhuri $\mathrm{S}$, Mitra SN, Banerjee PK, Biswas PK, Bhattacharrya S.

Immediate induction of labor in premature rupture of membranes at term (PROMT)-vaginal Misoprostol tablet versus PGE2 gel: a randomized comparative study. Int J Reprod Contracept Obstet Gynecol 2018;7:4048-55. 